\title{
We shape it, you make it: "Facing" and "Voicing" language-in-education policy in Barbados
}

\author{
Stacy Denny \\ The University of the West Indies \\ Cave Hill Campus \\ Cave Hill \\ Barbados, BB11000 \\ Tel: 246-4174463Ｅmail: stacy.denny@ cavehill.uwi.edu
}

Accepted: August 15, 2013 Published: Sep 02, 2013

Doi:10.5296/jsr.v4i2.4241ＵRL: http://dx.doi.org/10.5296/jsr.v4i2.4241

\begin{abstract}
This study examines language-in-education policies in other countries to determine the best kind of language policy for Barbados, the challenges which are presented by the process and feasible measures/plans for developing that policy. The aim is to convince policymakers of the need for an explicit, cohesive, 'humanised' language policy in order to improve the health of language education in the country.
\end{abstract}

Keywords: language policy, language-in-education policy, vernacular education, Bidialectalism

\section{Rationale \& research problem}

There is a lot wrong with the language education system in Barbados, for which many individuals, systems and organisations are culpable. This is not a criticism, but rather, a critique. The majority of Barbadian children come to school with a limited knowledge of English; they generally speak Barbadian Dialect (BD) as their first language. However, teachers insist that they speak Standard English (SE), and in some cases punish them for their use of BD. The majority of children in Barbados are failing to acquire SE proficiently after eleven or twelve years of studying the language; the language education system is failing them. There is no cohesive policy which addresses language use in Barbados, as well as no official language-in-education policy (LIEP). Additionally, and surprisingly, Barbados has opted out of a regional plan for language education policy (LEP) development for Caribbean states. Moreover, Carrington (1976) reports, and it is still relatively true today, that many researchers in the Caribbean states record the interaction between languages but few have attempted to determine language education policy for these states. It is against this backdrop of problems and tacit challenges that I chose to undertake this study. As an applied linguist, I cannot merely observe how these matters have given rise to much of what is wrong with the language education system in Barbados; I must also attempt to address them by means of research. This study therefore examines language-in-education policies in other countries to 
establish (1) the best kind of LP for Barbados, (2) some of the challenges which could be met in deciding policy for the territory, and (3) feasible measures/plans for developing that policy.

I hope through this research to convince policymakers of the need for an explicit, coherent LP, designed with the Barbadian people at its core, so that its design and implementation speaks to sensitivity, rationality and pragmatism as opposed to political agendas. I will attempt to persuade Barbadian policymakers of this need by clearly explaining what LP in a Barbadian context means, why it is needed, and how it can be properly designed, taking into account the possible challenges. This is with a view to avoiding some of the pitfalls of other countries, while adapting the things done successfully to the Barbadian context.

\section{Overview}

I begin by situating the research historically so that the audience has a better understanding of the state of policy currently. This is followed by the approach used to collect and analyse the data to reveal more about the research problem. I present my findings thereafter and the issues raised by them. I then attempt to draw reasoned conclusions based on these findings, which I believe can assist in designing the kind of humanized LP previously mentioned. Finally, I submit recommendations for designing the first phase of LP in Barbados.

\section{Socio-historical context}

There is no mention made of language education in the "Barbados Education Act" of 1997 or the "Education in Barbados Information Handbook" (2000), though there is some mention of it in the rationale sections of the Language Arts Syllabi for primary schools. These documents (Act and Handbook) reveal that the Educational Act Cap. 41 and Education Regulations of 1982 provide the legal framework for education in the country. The latter document, on which I will focus, because it is more current, claims that Barbados has a literacy rate of over $95 \%$ and that $18 \%$ of the government's annual budget is spent on education (very high in comparison to many other countries), and so understandably, the government expects to see significant returns for its investment. This is currently not the case; though it used to be in the distant past, on which I will now focus.

The Barbadian sociolinguistic setting is born from slavery. There was no provision to educate the slaves and their children as "planters considered it dangerous to teach the slaves a common language as this could lead to subversion aimed at destroying their property" (Handbook, p. 5). Ironically, the current goal is to teach one language, the colonizer's language, for purposes of cohesion. The year 1850 saw the first Education Act passed in the country, with an education committee being established with responsibility for education policy. In 1858 the second Act was passed, the curriculum was determined, the pupil-teacher system introduced and payment by results instituted. The students were to receive an education in the 3Rs. In 1890 another Educational Act was passed, and this was the principal Act until 1983, almost 100 years later. This is significant as it meant that the same Act catered to a growing educational system with changing, more modern needs. During this time an education board replaced the committee, and there was an inspector and assistant inspector 
appointed, as by 1906 about 10,000 were being educated. By 1907 the contention was that the Board lacked a definite policy and that education in the First Grade Schools (most prestigious secondary schools) was "severely academic...having little contact with reality" (Handbook, p. 8).

In 1973 the National Curriculum Development Council was launched and a curriculum division established in the Ministry of Education. In 1983 a New Education Act was proclaimed, and that Act, some 30 years later, still governs education in Barbados. The compilers of the handbook suggest that: "The Act is comprehensive and covers all aspects of education" (Handbook, p. 15), though it never mentions the vital issue of language in education in this bi-dialectal (coexistence of BD and SE) context. The period 1983-1995 saw the introduction of remedial teachers of reading and Maths in almost all primary schools. This is the only near mention of the use of language in the document. In 1995 "The White paper on Education Reform: Each one matters" was drafted. It was stated that this document "spelt out the Ministry's policy in relation to...the teaching profession; curriculum reform, special education..." (Handbook, p. 16), but still, there is no mention of language in education.

\section{Methodology}

Research questions

I knew what I was looking for in the literature, but I was unsure about what I would find, and so I formulated four research questions to focus my reading. They are as follows:

- What should language policy mean in a Barbadian context?

- Which is an explicit language policy advantageous for Barbados?

- What challenges are presented by the language policy process?

- How can the language planning/policy process in other countries inform the Barbadian context?

\section{Research design}

The research questions better helped me to determine the methodological approach. I chose a qualitative approach in the form of a survey study, but not in the typical sense of surveying participants to obtain and then compare/contrast their views; rather, I chose to survey the literature to compare and contrast issues concerning LP. I was confident that a qualitative approach best suited my objective of deepening my understanding of how language planning and policy are "perceived" and "experienced" (Carr \& Kemmis, 1986: 90) by those researching the field and those impacted by policy, in order to come away with a clearer representation of the process which would provide the framework for language planning and policy in Barbados. This study is also historical, as I evaluated policies already drafted/implemented to determine future LP for Barbados. I therefore analysed the data in the literature to establish how any proposal for an official LP in Barbados squared with investigations already conducted primarily in other similarly culturally-situated places to hopefully avoid the mistakes others made and capitalise on their successes. Because accuracy of sources is critical to this kind of research, to properly represent the truth of the data, I 
chose to rely mostly on primary sources, people who have themselves collected the data or reported on them first-hand.

I compiled the data from the literature in the field. The sample of literature I used adequately represents the context to which I make application, as it speaks to LPs in post-colonial territories, particularly, African states, where there is coexistence and competition of a standard language and one or more non-standard vernaculars operating in the language classroom. In these contexts, like Barbados, the non-standard tends to be spoken by the majority and the standard by the minority in the community. The latter is the primary, if not the only, medium of instruction in most instances. I also surveyed literature about LP in the developed Western nations (US, Canada, UK, Europe), as these policies tend to heavily influence those of smaller nations like Barbados, and so it would be easier to convince policymakers of an LP plan if it aligned with those of larger more established economies.

\section{Data Collection techniques}

I first did an online index search using the key terms "language planning" and "language policy" in various educational databases. Evidently, this area was well researched and documented, so I limited my search to the period, 1990s-2013, to narrow the scope. I further narrowed the search by focusing primarily, though not exclusively, on LP related to education in territories with a similar socio-historical background of colonisation to Barbados; although, I also consulted works from the developed western nations. As I read, I coded the information, allowing for categories to emerge naturally, then I revisited the coded material and categorised the information until I felt I had exhausted the categorisations which would assist in answering my research questions.

\section{Data Analysis techniques}

The data were then analysed by identifying the categories, looking for similarities and anomalies, and discussing them in line with the research questions and the literature in the field. Additionally, I drew out relevant implications from the findings, which helped me to analyse the findings at a deeper level, perhaps in ways not tackled in the literature.

\section{Limitations}

Though I have not read every piece of material written about language planning and policy, I have included the works of leading scholars in the area, people to whom others give recognition in their own work. This strategy is obviously advantageous, as most people quote the work of these scholars, so this group of scholars served as my primary sources. There are limitations to the actual sample size used, in comparison to the actual population (everything ever written on LP). I believe that narrowing the field to post-colonial territories during the period of the 1990s-2013 helped to better reflect the current sociolinguistic trends in LP which are compatible with, and suitable for application to the Barbadian context. The issues might not be identical, but they are similar enough to warrant being part of this research, having been shaped by similar socio-cultural factors; thus, rather than being a narrow focus, my choice of territories was expedient. 
The other limitation is my inexperience in the field. I am however making use of the expertise of my colleagues around the world as well as reading copiously around and within the area. While this will not make me an expert anytime soon I have chosen to adopt Wright's (2004) thinking on the matter, that while language policy language planning (LPLP) requires an interdisciplinary approach, making it "risky... to go beyond one's own training...in the LPLP context, it may be even riskier not to do so" (p. 3 ). The risk is to underestimate the importance of this issue to social and economic development. If Barbadian policymakers have chosen not to participate in a language forum, as part of a larger Caribbean group, to deal with this concern, they have not recognised the importance, and so I will bring the importance of this matter to their attention in a small voice until I get a quorum.

\section{Findings and Discussion}

Overview

In this section, I present the themes emerging from the readings and then discuss them in the following major categories; Defining LP; Rationale for explicit LP, Challenges, and Recommendations for proceeding.

\section{Defining $L P$}

I found that there is no single or cohesive definition of the term 'language policy'; the motives for LP were not always altruistic or in the best interests of the majority as they neglected to address the thorny issue of social equity. Additionally, I found that poor planning usually led to abandonment of policy implementation or poor implementation results.

\section{Research question 1: What does LP mean for Barbados?}

It is not my intention to provide a lesson in LP. That lesson can be had from any major text in the field. I am, in this section, trying to establish a definition/description of this term relevant to the Barbadian setting. I believe that because this discussion arises from a critique of the educational system, this is where the conversation should be centred and debated; hence, LP for the purposes of this study becomes language-in-education policy. I will not be attempting to answer the question of which language should be used in the educational system, but rather, argue that any language used should be done so in a more deliberate, systematic and meaningful way so that students can see the link to their own lives in the act of communicating.

I must clarify that LIEP is not language policy or even language education policy, though it sits within these areas. LP for example, can arise from societal issues and cultural processes (Cumming, 1997), that is, it can be a response to a larger social issue, like immigration or employment, such as identifying one or more languages as official or working languages in a country (Phillipson, 2003). On the other hand, language education policy refers specifically to how language is used to conduct the business of education, for example, how language learning will be organized in education at all levels and what language will be used as the medium of education (ibid). LIEP is an important component of both policies and as such, 
Phillipson (2003) speaks to its role as involving regulations and policy statements prescribing learning of particular languages in education whether as a first, second or foreign language. It also involves laws/measures that specify the rights of speakers of majority and minority languages to use their language in education. Additionally, he explains that LIEP aims to provide citizens with linguistic competence in a range of languages for general and specialized uses.

There are core elements of LIEP which overlap with LP and LEP. For instance, decisions on related matters of language use are taken by government (McGroarty, 1997; Spolsky, 2004; Reagan, 2010; Phillipson, 2003). These can be written in an official document as explicit statements or they can be implicit, expressed in views and practices. The caution is not to be fooled into thinking that an "[a]bsence of explicit status policy measures [would]...imply that no language policy is in force" (Phillipson, 2003: 14) as "language policy exists even where it has not been made explicit or established by authority... so that the nature of their [countries'] language policy must be derived from a study of their language practice or beliefs" (Spolsky, 2004: 8). LIEP can be explicit or implicit, and can be successful in either form. In Barbados, LIEP appears to be primarily implicit, with a few sentences about language use documented in the Language Arts syllabi.

Language planning is sometimes used interchangeably with LP. Phillipson's (2003) description of language planning clarifies their meanings by espousing three levels of policy (status, corpus and acquisition planning), which come under the umbrella of language planning. My interpretation of his description would look like the following:

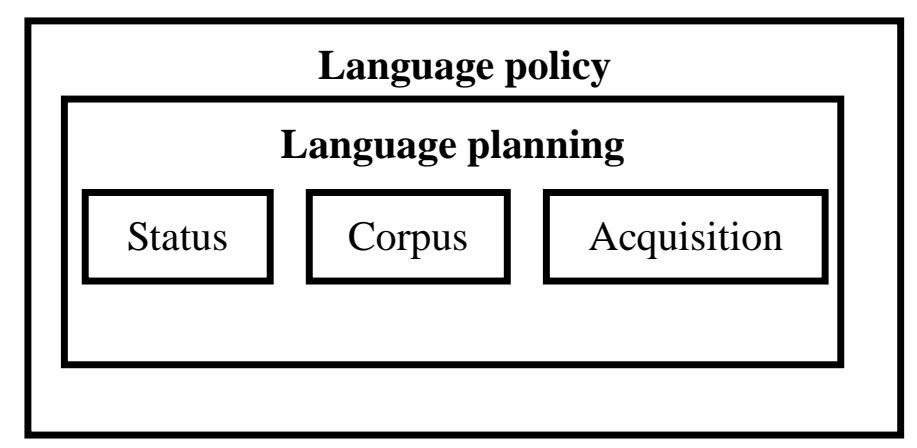

Figure 1: Illustrative definition of LP based on Phillipson (2003)

In this model, language planning is at the core of language policy. Planning appears to drive policy, and when each planning level combines, it becomes policy. In brief, language planning in its totality (all three levels) is language policy, but separately, just part of language planning. Reagan (2010: 31) might disagree with such a description, as he proposes that language planning "is...an...activity resulting in the development of specific language policies". Rather than being policy, language planning initiates policy, so one arrives at policy through planning; planning is the act; policy is the product. So which is it? Is planning 
policy, is it part of policy or is it the stimulus for policy? I guess it depends on who we ask. Phillipson's (2003) viewpoint elucidates the discussion in proposing that likely "in a context where the term 'language policy' is in active use, it is understood in a specific, focused sense" (p. 17). LP is therefore understood by the individual(s) as s/he experiences it. Drawing from this conclusion, I will attempt a description based on my experience with implicit LP in Barbados and my vision for an explicit LIEP.

\section{Definition/description of LIEP}

My own experience, or inexperience, is the path I have travelled to my definition of this term. To describe this term I focused on my area of specific interest, language use in education, and the context in which I observe policy "play out"; namely, Barbadian classrooms. I reiterate that I determine LP in this context to be LIEP. I see this term specifically as (1) identification of language problems anywhere within the educational system, (2)research of these problems to offer an informed position, (3)possession of a determined will to address and rectify the problems, (4)dissemination of information to those within and outside the system to gather support/assistance, (5)development of a network of people for putting remediation plans in place, (6)management of these plans through interventions of maintenance, modification, elaboration and rejection, all the while working alongside the right individuals and agencies and involving the public, (7)targeting change at the level of public perception and legislation, (8)encouragement/advocacy and implementation of change at the level of the community and education and finally to borrow Haugen's (1966) idea, (9)elaboration of the policy, by putting measures in place to continually modify the policy to meet the requirements of modernization and development.

A few things stand out for me regarding this description which might not have been overtly expressed. Firstly, this process might start off linearly, but at some point it will become cyclical, also, at each stage of the design, the public is involved as LIEP affects them directly or indirectly. Secondly, this process should not be a top-down initiative even if it is initially driven from the top. Language is a community system and so LIEP should be a community effort. Admittedly, there will be stages where the community will be less involved; still, this should not mean that they ought to be less informed. Finally, I conclude that language policy is language planning; we plan for policy; we plan policy; and we put plans in place to deal with the effects of policy. Policy is not merely the result or the sum total of the planning effort, as there are many results attained along the way, even if the goal of written documentation is never achieved. I chose therefore to define LIEP in this way because, although I advocate an explicit LIEP, if I only think of language policy as written documentation, I might be short-sighted about the victories achieved in moving towards the goal of remedying some language problem. In essence then, $L P$ in the context of Barbados is LIEP, which is a process, linear and cyclical, with language planning and the public at its core, on the path to remedying some language problem(s) in education. I will now move on to answer the central question: why does Barbados need an explicit LIEP?

Research question 2: Why need for explicit LIEP?

There are several reasons why an explicit LIEP is advantageous for Barbados at this time. 
Many of them at first glance do not appear to have a link to LIEP, but I will weave them into the presentation of my argument. Some of the reasons I expound here are a need for (1) guidance in teaching practice, (2) heightened teacher awareness as to his/her role in LIEP, (3) channels to address teachers' limited proficiency in SE and underperformance in national English language exams.

There is a need for an explicit LIEP to guide English language teachers (ELTs) in their expectations. Teachers should know what is expected of them as to what to teach, how it can be taught for maximum benefit, how language learners learn and what help they can obtain to improve their own proficiency levels in SE. In Barbados and the rest of the Caribbean, a significant percentage of teachers are untrained, over fifty per cent (Obidah, 2011) and so the first time they teach they not only lack training, they also lack in-class support. They present not sure of what is expected of them, having texts but no knowledge of classroom management, less knowledge about teaching and some knowledge of the subject because of having been students themselves. I am speaking from experience. Carrington's (1976) exposure to this issue is therefore as true then, as mine is today when he says that:

Certainly, in the Eastern Caribbean islands where English is the official language, my recent experience with teachers has been that there is a feeling of anxiety, insecurity and helplessness over how to put into practice the enlightened views presented to them by language education experts (p. 35).

Sometimes teachers really do not know what to do in the classroom, with or without training, and this brings me back to the central question: how can an explicit LIEP help? Firstly, it makes implicit policies more concrete and rational for guiding ELTs in the classroom. This implies the formulation of LIEP that reflects an understanding of the kinds of knowledge ELTs should have to be successful. ELTs should not only possess deep content knowledge, they should also know "something about how that content is taught and learned. If they learn a series of specific teaching techniques without understanding their rationale and without help in adapting them to particular students and classroom situations, they will be unable to make lasting changes in their practice" (Kennedy, 1991: 17). That help can come in the form of quality teacher training, and so an explicit LIEP for Barbados would stipulate training for all pre-service ELTs in English language teaching (rationales, approaches, strategies, and methodologies) in bi/multi-dialectal contexts. This policy would also specify a period of continuous training for in-service teachers to ensure that their competencies and skills are up-to-date, because "majoring in an academic subject in college does not guarantee that teachers will have the kind of subject matter knowledge they need for teaching" (Kennedy, 1991: 14). An explicit LIEP also nudges schools in the direction of drawing up formal school language policies in line with recommendations made at governmental level. These school policies would be even more detailed in outlining teacher expectations for that specific school environment, and certainly this should give ELTs clearer direction.

An explicit LIEP can help teachers to understand their role in policymaking. ELTs should no longer see themselves, nor have others see them, as mere implementers of policy. After all, they are so close to the language problems, being "on the ground", that they can serve in their 
capacities to identify these problems, speak to them intelligently, bring them to the attention of others and even attempt to address them, granted that the necessary resources are available. They can even assume the role of soliciting these resources. A LIEP process which involves teachers from the start helps them to begin to understand the relevance of language and language-in-education policy to their work in the classroom (Kaplan, 1997). Additionally, they learn to implement "more pro-active and ethnically inclusive language policies in their own situation" says Wren (1997: 4). I wish to take a moment to take issue with the thinking that might have shaped Wren's comment about teachers implementing proactive policies. The suggestion is that ELTs know or feel that they are entitled to get involved in shaping and influencing language policy. Such thinking is shaped by cultural practices. In Barbados, ELTs have been trained to see themselves as implementers of policy. Unlike Wren, who states that she discusses leadership and language policy in ESL with her teachers, many teacher trainers in Barbados do not, maybe because they too see teachers as implementers. The challenge in the Barbadian context is not simply one of opening up the discussion but re-wiring the mind-sets of teachers and trainers to appreciate that ELTs are integral to the LIEP process from start to finish. Wren also assumes that ELTs are adequately aware of "their own situation", that is, their socio-linguistic context. To explain, after three years of majoring in Linguistics, teachers still tell me that SE is the native language of Barbados. The point is that such wrong thinking will impact practice, perhaps to the detriment of the majority dialectal speaking students. An explicit LIEP should therefore take into account the need for ELTs to be trained in areas which target attitudinal change (for e.g. Language diversity, Bi/multi-dialectal methodologies, Language and identity, Cross-cultural communication) rather than just theoretical Linguistics which might only target content knowledge. The ELT must therefore become a policy planner. S/he must assume the role of influencing policy makers through informed critiques, articulation of myths and facts about language teaching and addressing emotional valence of popular beliefs about language and language learning (McGroarty, 1997). In effect, they should become informed advocates (ibid). When ELTs have more control over LIEP decisions, they will feel more empowered in their classrooms, and not as though decisions are being made for them, without them. This might even make them less resentful of, irritated by, and resistant to, the implementation of policy.

An explicit LIEP would anticipate and target obstacles which could affect the success of its implementation. An ELT's limited proficiency in the language would fit these criteria. Teachers who are not proficient in the language tend to be poor teachers of it. Unfortunately, several ELTs in Barbados and the Caribbean are not adequately proficient or consistent in their use of the standard (Denny, 2007, 2010; Aberg \& Waller, 2012; Robertson, 1996; McCourtie, 1998). Some who are conscious of their limited proficiency are ashamed to ask for help (Denny, 2007). The result is the reinforcement of a hybrid of SE and BD, and so students leave school not having been taught the correct grammar of SE. This state of affairs is by no means unique to Barbados or the Caribbean. Mangubhai and Mugler (2006: 55) in quoting the Fijian Development Plan 1966-1970 explains that the reason English could not be declared as the medium of instruction in primary schools "lies in the average teacher's own poor command of the language". An explicit LIEP would serve to be proactive, and so it 
should stipulate a minimum requirement of linguistic proficiency for entry level into the profession. It would also set out statements requiring linguistic training, then assessment, of all in-service ELTs. In essence, this policy would ensure in the future that no teachers come directly from secondary school into the English language teaching profession, which is so crucial to successful language building. By means of this policy, policymakers and those involved in the process demonstrate a level of seriousness and commitment about who becomes part of the English language teaching core. The goal is to have a cadre of professional, highly proficient, insightful ELTs, rather than just "warm bodies at the front of the classroom" (Kaplan, 1997: xvii). In other words, only when policymakers, through their representatives in the Ministry of Education, take responsibility for the kind of "professionals" entering into the English language teaching service can this area of teaching attract the consummate professional. An explicit LIEP proactively weeds out unsuitable ELT candidates while giving, through training, less proficient in-service ELTs the opportunity and support to improve.

An explicit LIEP puts measures in place for the most meaningful kinds of ELT training. ELTs in Barbados have been trained to test aspects of the language rather than to teach them then test them. This is part of the over-prescriptive nature of ELT in the region which emphasizes testing in order to train students to pass national and regional examinations. I am not blaming teachers because they too have been educated in the same system and further trained in it, so that it has become a part of the "teaching normal". To add clarity to this point, many of the teachers I train have admitted to testing rather than teaching for comprehension. In fact, the first time some of them knew that comprehension strategies existed was while taking an English language teaching course as part of their university training, which can be many years after being in the teaching service. In some cases, these teachers would have already gone through teacher training. Personally I do not agree with teaching students for exam purposes, especially in a language in which they will be expected to function socially. Academic language is not always reflected in real-world language and so the technique of prepping students to pass an English language exam is, and will always be, problematic when they have to make application to the real world. An explicit LIEP for Barbados could speak to the nature of training teachers receive, stipulating methodological and pedagogical training in real-world communicative techniques, so that teachers can help students learn how to apply their linguistic knowledge outside of the classroom. The fundamental point herein relates to why Barbadian citizens need to know and learn English. This is the question which should shape effective LIEP in this setting. I think even more pressing is the question of why Barbadian citizens presently need to learn English, as opposed to long term, because language needs do change over time. The formulation of an explicit LIEP would give policymakers the opportunity to critique these issues at a much deeper level and thus, better ably understand how best to tackle the source of the language problem instead of having to clean up the mess that spills on to the surface.

An explicit LIEP is required because presently the implicit LIEP is proving to be inadequate. It promotes English for academic purposes but most students fail to adequately attain to this 
goal. The underperformance of students in English language exams (see appendix 1) reflects poorly on policy interpretation of the language situation, which indicates that this policy is failing in its objectives. This is similar to the way in which Hebblethwaite (2012) speaks of the Haitian situation. He says that historical, sociolinguistic and demographic factors can explain Haiti's low educational achievement, but then he adds very profoundly: "Another important but often ignored factor is educational language policy" (p. 1). When ignored, an implicit policy, which when explicitly interpreted, forces SE monolingualism on monolingual vernacular learners in a system where teachers are bi/multidialectal, but not highly proficient in the language they teach. This equation must spell disaster, so that when we arrive at the cross-roads where the educational system no longer meets the needs of the students; yet, tax-payers are paying out increasingly more for education, we need to sit-up and ask some hard questions. Where there is a high level of underperformance in the school system, it should provoke reflection, critique, and alternative models, says Hebblethwaite (2012). An explicit LIEP gives Barbadian policymakers the opportunity to do all of these things. Barbadian students have a right to quality education, but tax-payers also have that right because they are paying for it. A high level of underperformance in national/regional English language exams is arguably a justifiable reason for having an explicit LIEP in Barbados. The process of LIEP could begin to shed light on this aspect of language education (underperformance) which needs more thorough investigation if it is to be rectified. Such investigation means that language education should no longer be based on myths and opinions, but on solid research evidence. This approach could assist schools in finding ways of increasing student and teacher linguistic proficiency within a bidialectal context.

Most importantly, there is a need for explicit LIEP in determining the role of BD in education. Many teachers are unaware of the policy related to dialectal usage in the classroom because it is so implicit it is almost obscure. For example, the Language Arts Syllabus for primary schools alludes to BD in this statement when speaking of "a bridge, which allows for a smooth transition from oral proficiency in the native language, to full communicative competence in Standard English" (p. iv). What is the native language to which they refer? Will this not be incorrectly interpreted if teachers honestly believe that the native language of Barbados is SE? Are teachers even aware that this statement exists, because they usually tell me that they are expected to use only SE in the classroom; perhaps, because they are more focused on the opening statement of the rationale which "foregrounds" this document. It reads: "The ultimate aim of the Language Arts programme in the primary school is to develop students who are communicatively competent in Standard English" (Language Arts Syllabus, p. iv). On this basis, ELTs could make the assumptions that SE should not be used in the classroom because this is what the Ministry of Education expects them to understand. However, the result of what they assume leads ELTs to use BD in many ad hoc ways (as punishment, to show disapproval, to explain, for creative arts sessions (Denny, 2002); yet, they refuse to allow the child to use the language. The child then becomes confused, frustrated and disillusioned about the language learning process as they associate their use of the mother tongue with reprisals. Corson (1997) aptly describes the situation:

education often routinely represses, dominates, and disempowers language users whose practices differ from the norms it established....This unjust 
misdirection in policy routinely disadvantages those...who value and use discourse norms or language codes that attract a lowly status in conventional schooling (p. 150).

An explicit policy nullifies the excuse for avoiding the standard vs. non-standard debate. The disregard of $\mathrm{BD}$ as a legitimate educational tool is at the core of the language educational problems in Barbados. No one wants to speak about the white elephant in the room (BD), but no one will see any real progress until they do. It is absurd that the term "Bajan Dialect" or dialect cannot be used in the Language Arts syllabus. Explicit LIEP would open up this discussion, and thus, as has been done in Jamaica, recommend options for language teaching which incorporates the use of the vernacular (The Jamaican Language Unit website).

There are several other reasons having an explicit LIEP in Barbados is advantageous. Ethically, this policy is more than about teaching students English. It is also about "ensuring equity gains for students" (Wren, 1997: 10). What do I mean by this? A coherent LIEP in Barbados would highlight the importance of BD as a cultural and educational tool. Literacy in BD has the potential of providing access, "the bridge", to the dominant discourse language. Wren admits that those who lack this discourse language cannot participate in the discourse; hence, having very little power in making decisions which ultimately affect them. LIEP can give a voice to the otherwise voiceless, a face to the faceless, because policymakers might stop seeing this as a political/educational issue to seeing it as a human/humane issue, an issue not just about rights, but an issue about right and wrong. An explicit policy also makes policy documents public and visible through writing (Shohamy, 2006) so that people have access to query, critique, and offer recommendations. Everyone, including policymakers can then be held accountable, but they can also feel a sense of ownership of this policy. If people feel responsible then accountability means something. Accountability brings a fair measure of responsibility and I believe that people in Barbadian education need to take responsibility for the education system that they serve, rather than laying blame for poor linguistic performance squarely at the feet of students and teachers. An explicit LIEP helps us move forward from the blame-game on to the business of building education from the foundation of language.

\section{Research question 3: What are the challenges facing LIEP?}

Overview

The LIEP process can become over-politicized and de-humanised. In other words, it becomes more about politics and less about the people and educational system it should serve. Granted, policymaking is political but the challenges come in the form of improper and selfish motives, over-involvement of politicians, disregard for planning, inaccessibility to social equity and vague aims.

\section{Over-politicizing}

From design to development, some LIEPs are nothing more than "political football" Cumming (1997: 99). Spolsky (2009) in speaking of the US situation concurs, adding, "...school language policy, it seems, is politics, and not science" (p. 102). In India, Fatihi (2001) reveals that linguistic issues are manipulated to achieve certain political ends. These 
policies are self-serving. Furthermore, because the LIEP process is sometimes heavily politicized in favour of the elite, it means that those who are most disadvantaged socially are further impacted educationally because of inaccessibility to the dominant language of discourse in education. For instance, in South Africa, the Minister of Bantu Education at the time, H.F. Verwoerd made it extremely clear that LIEP was designed to separate the races, so that natives (Blacks) would understand from an early age that they were unequal to Europeans (Christie, 1991). It sounds outrageous, but at least he was overt in his intentions. Others are more covert, but no less sinister. The fact is that policies "are made by, and reflect the interests of, those who dominate the state policy-making apparatus" (Tollefson 1991: 203). I do understand that "language policy research and scholarship must be understood as a socially situated practice that reflects particular interests and ideologies" (Ricento, 2000: 8), but those interests must be more closely in line with those of the socially and educationally disadvantaged if the entire state is expected to benefit, for an educated society lays the groundwork for a strong state, economically and otherwise.

Proper and sufficient planning for, during and after the process, along with shrouding policy in vague language can be challenging. The Malawian situation exemplifies these challenges. Kayambazinthu (2004) reports that on March 28, 1996, the Malawian government decreed that children in all schools (standards 1-4) would be taught in their vernacular languages. This would appear to be a win for those struggling in the official school language, English, but the reality was that this policy "typifies a policy-by-decree approach that was not based on any research or proper planning" (p. 122). According to the author, there was no prior training of teachers, no preparation of materials/resources and no research into sociolinguistic community attitudes. If this is not enough, some policymakers shroud LIEP policy in such vague language, that it can be interpreted in several different, even contradictory, ways. A policy may for example speak of 'respecting' and 'showing appreciation for', or 'valuing' the vernacular, but what does this mean in real and practical educational terms? How is the teacher to understand the way(s) in which this should be translated in teaching practice? S/he could ignore/ban its use in the classroom, but still claim to value and appreciate it (Denny, 2002). While I understand that being too specific could hem in the practitioner, the policy cannot be so vague that it is open to ambiguity. Basically, it comes down to this question for teachers: should we use the vernacular in our instruction? If so, how can we incorporate it? LIEP needs to address the real issues, even the uncomfortable ones, in its planning if it is to overcome the kinds of challenges identified here. Avoiding difficult issues will simply cause them to grow bigger, so that any planning will always appear improper and insufficient when more issues emerge than solutions can be found.

\section{Attitudes}

There will be negative attitudes threatening to disrupt the LIEP process, and this can be a challenge. Attitudes are manifested in the form of views/actions based on these views, and will at times show solidarity and at other times prove conflicting. Teachers' negative attitudes to students' language is bad policy and practice, but can easily be encouraged through vague policy. The real challenge is adjusting the views of policymakers and teachers to language 
learning. Some teachers perceive students as unintelligent because they have limited proficiency in the school's language, but teachers have been abetted in this view by policy. Teachers can hide behind a policy which says that children should be taught English. When children are taught English but do not master it, teachers can still argue that that they have done their jobs according to policy; they have taught English, but have they taught the child, addressing his/her needs. Some ELTs do not overextend themselves because they already "write off" a child as incompetent in the language. The point is that policy seems to unwittingly encourage English as the medium of education, as though it were the same as medium of instruction (John, 1969). We should instruct students through a language so that they can educate themselves, and this is why John (1969) argues that instruction should be in a language that the student knows well. The approach to teaching students the school language should be as simple as adding to their linguistic repertoire, but unfortunately this is not the case. The teacher, through implicit policy, interprets the language learning situation as one where the child is lacking English (Corson (1997) and responds with the "conventional policy" (ibid: p. 151), of ignoring students' first language and replacing it with the school language. If ELTs, through policy, interpret the language situation incorrectly, it probably means that policy has interpreted the situation incorrectly, and so both teacher and policy will respond inappropriately. However, this challenge can be overcome by examining the linguistic realities and adopting clearly spelt out policies that reflect them, because "with a well-designed and explicit national policy, less scope exists for a conflict of interest between the needs of the mother tongue speakers and second language needs" (Corson, 1997: 159). Any LIEP which knowingly or unknowingly condones or reinforces negative attitudes to children's language and to language learning, only serves to promote poor language education, and no country wants to be known for providing poor quality education to its citizens in the eyes of the world.

There is a challenge to avoid turning personal ideology into policy and then policy into practice. People's views are shaped by society, and politicians and teachers are bred in these societies, which ultimately shape their views also, so why should we expect them to think outside of the societal box? Through education we have been taught that the school language is the saviour and any other competing language is the villain blocking passage to that saviour. This belief is made more credible when disadvantaged people, presently politicians, have seen opportunities open up because of their acquisition of English, so naturally they believe in the "power of English" and begin to legislate "cultural imperialism" (Eggington, 1997a: 43). Undoubtedly we need to be realistic and practical; we need our children to learn English to have access to modern knowledge. We want them to have the many kinds of opportunities that acquiring this language brings, but the point still remains that after many years of studying the language, they are, for the most part, woefully inadequate in its use. The ways we learned English helped us and were perhaps appropriate for our generation, but they are not working today. If we hold on to our ideologies and cement them into our language policies, it is hardly likely that we will be the ones suffering educationally. We need to start asking the questions John (1969) asked over forty years ago if we are to move towards rational LIEP, shaped less by ideology and more by pragmatism, such as: What language(s) 
will give us access to the knowledge we seek? What language(s) will help us most in achieving self-expression and communication, and what language(s) shall we need for securing good employment? (p. 34). Answering these questions realistically can help to shape the right kinds of LIEP.

The attitude towards the content of LIEP can be particularly challenging, but not in the way we might think. After all of the planning and hard work, the public might show very little interest in LIEP. For those who know what it took to get it to that stage this could be somewhat disheartening, particularly if they require feedback for its improvement. I am here drawn to Tollefson's (2002) thought provoking statement that most people's attitudes to LP and the rationales given for them are simply to accept the document at face-value. While I agree with this view for the most part, I also recognise that the people whom are most affected by these policies tend not to even understand the language in which they are written, not just the actual language, but the complexity of the structure of the language. They probably have never been given access to this documentation, so that what might appear to be apathy is really a lack of understanding of how the entire process truly affects them, as no one really takes the time to explain it to them in a way they could understand. We would want to avoid a situation, as sometimes occurs, where the very policies put in place to allow the disadvantaged access to the language of power, entail other policies that bar them from that very access. Ball (1994) for example, illustrates how the enactment of one policy can contradict or negatively influence the enactment of others, and sometimes it happens that although "states may fund language programmes and proclaim the importance of language learning, they simultaneously create conditions which make it virtually impossible for some citizens to acquire the language competence they need" (Tollefson 1991: 202). Any LIEP for Barbados must avoid the trap of catering exclusively to the elite, as it now appears to do, and take the opportunity to give voice to the voiceless by picturing their faces in this policy.

Another challenge is the view we take of LIEP. I have fallen into the trap of viewing LIEP simplistically. I used to see it as "simple dichotomous relationships between monism and pluralism" (Pennycook, 2000: 59). In my mind, educational minority monolingualism in a majority bi-dialectal context is unjust, and I still believe that, but in the past I approached this issue in a vacuum, through sentiment, separated from context. I still hold this view, but I am forced to reason it out logically, by placing it in a sociolinguistic and political context to make sense of it. Pennycook (2000: 59) is therefore spot-on in his assessment of this challenge:

in order to make sense of language policies we need to understand their location historically and contextually...we cannot assume that promotion of local languages instead of a dominant language, or promotion of a dominant language at the expense of local languages, are in themselves good or bad. Too often we view such questions... without understanding the actual location of such policies.

For example, according to Barkhuizen and Gough (1996) the promotion of mother tongue languages in South Africa was the instrument used to maintain apartheid. It was morally 
wrong some might say, but it was politically expedient. Historically and culturally, it served the purposes of the ruling class, wrong or right. It therefore comes back to these questions for educators and policymakers in Barbados: what is the real purpose of language education in Barbados and how can this be reflected through policy?

\section{Language teacher proficiency}

Another major challenge to LIEP is limited teacher linguistic proficiency. LIEP is affected when teachers do not have the language proficiency to make its implementation successful. This is a very serious topic as assessed by Probyn, (2005: 157), who contends that teachers' limited proficiency of English in South African classrooms "may reduce opportunities for language development" on the part of students, as they are oftentimes only as proficient as the teacher herself. The implications are obvious. LIEP must consider as paramount the professional and educational quality of those implementing policy. Policymakers, like teachers and students, must be held accountable when there is implementation inertia. The very policies that they make must hold policymakers "accountable for ensuring the conditions and resources necessary to create and maintain a system of excellence that offers universal opportunity" (Welner \& Carter, 2013: 4). If teachers are not implementing policies, policymakers must explore and seek to address the issues which prevent them from doing so. Poor quality teachers must also be seen in the light of poor quality policymaking and by extension poor quality policymakers.

Another challenge regarding policy implementation relates to code-switching in the classroom. The act of code-switching can speak to a teacher's level of proficiency and the quality of the instruction dispensed. Martin (2005: 88) states that though code-switching is common in the classroom "it is often lambasted as "bad practice"", or "blamed on teachers" lack of English-language competence". I will argue that implicit policy forces ELTs to operate covertly with regards to this matter, but in reality teachers who operate in a bi/multi-dialectal context must code-switch. I contend that it is not only necessary, it is humane. In Malaysia, Martin (2005: 88) highlights that the "clearest disengagement with language policy in the classrooms observed is that other linguistic resources are being used alongside the official language of the lessons". I believe however that the problem is not code-switching, but the ad hoc way in which it is done and the contradictory messages it sends. Teachers admit to feeling that they are doing wrong by incorporating the non-standard into the English language classroom (Denny, 2010; Probyn, 2005), and so there is no coherence in its use. As a result, students are perplexed when they are scolded for their use of the non-standard, but the teacher freely uses it. These actions send mixed signals to children who are already struggling with the standard school language. Although Probyn (2005: 162) lists a range of circumstances in which teachers code-switch, the point remains that this range can easily be viewed collectively, even coherently under the microscope of research, but in teaching practice it appears to the students that there is very little structure to when and how the teacher incorporates the vernacular.

The problem here is one of policy and training. The matter of code-switching speaks to 
whether training programmes take seriously the realities of language use in the classrooms (Martin, 2005). It also speaks to the teachers' responsibility to the language learners, of communicating with them, while balancing her responsibility to implementation of policy. All of these issues can be encapsulated in Corson's (1997: 151) question: "Should ESL teachers adjust their professional practices to become bilingual educationists rather than just second language teachers"? When ELTs truly begin to understand that they do not teach English, but rather, they teach students to use English proficiently, English language teaching stops becoming a subject on the curriculum and becomes a service. Armed with this knowledge in their minds and hearts, teachers are in a better position to desire to give the best service to their students. LIEP must therefore become part of the support system in helping to change teachers' ideologies and policies about vernacular language use in education. Teachers should be helped to move past seeing "code-switching as illicit" (Probyn, 2005: 163) and instead devise deliberate, well-planned, coherent intervention strategies which support the use of vernacular in the classroom for the benefit of the students. This can be achieved through policy measures which ensure that training colleges properly prepare teachers for the realities of language teaching which involve code-switching.

Policymakers should not allow the choice of a medium of instruction to become the major challenge. Most experts agree on the cognitive, educational, social and psychological benefits of vernacular education (Siegel, 1997; Ferguson, 2010). The issue then can no longer be centred on which language should be used as the medium of instruction; the issue is not to make an issue when vernacular language use is encouraged in the classroom because this kind of education has been shown to yield positive results. In other words, this is not a competition between the standard and non-standard; rather, policymakers, with the help of language experts familiar with the socio-linguistic context, must seek ways of incorporating both varieties; perhaps, for different subjects or for use at different times of the day (Ferguson, 2010), so that the issues move away from the stale debate of what to use and on to how to use them and when. John (1969) invariably says it best: "it is important to remember than in choosing the medium of instruction, the mobility of scholars and even the unity of the country are secondary considerations. The first thought should be: "what is the most effective means of communication between teacher and student" (p. 38)? There are some cases where even the most seemingly complex issue can be easily resolved by adopting a realistic stance.

\section{Resources}

Resources present one of the greatest challenges to LIEP implementation. Limited/no resources even with the best of intentions can stall or halt implementation of the most carefully planned policy. As is typical of developing nations, Probyn (2005) laments that in South Africa, "the lack of resources in many schools constrains their capacity for effective engagement with new policies" (p. 160). This problem is not restricted to developing nations though, as Cumming (1997) shows that "resources for English language education have remained limited...because Canada has rarely pursued an active policy of English as a Foreign Language education overseas...” (p. 102). Welner and Carter (2013) in making reference to the USA are adamant that "[r]ecent policy has attempted to solve problems on 
the cheap" because policymakers have neglected "investing in the key community needs and classroom resources necessary to create engaging, supported learning and learners" (p. 3). The issue clearly becomes: how seriously is language education being taken by educators and policymakers? Do policymakers see it as does Kaplan (1997) whose perspective is that language education lays the foundation for all other types of education and thus, "language teachers...ESL teachers among them hold the highest place in the teaching profession" (xv)? If policy makers are skimping on resources for language education this means that they should not demand the best from teachers and should not hold them accountable for the successes of their students, when in fact they too neglect to give of their best to language education. Policymakers should be helped to see language education, through LIEP, as an investment, rather than an expensive burden. The truth is that people allocate resources to the things they see as important, and perhaps this is not simply a case of lacking the resources to provide the resources, but viewing language education as less important in the grander scheme of things (e.g. healthcare, science \& technology). This is the point at which all involved will have to do some serious soul-searching by returning to that very pertinent question: What is the purpose of language education? Is it simply to serve the interests of the dominant group (Tollefson, 2002), or help people get jobs (McGroarty, 2002) or is it to respond to students' needs by giving them a fair chance at academic success (Welner \& Carter, 2013) or create conditions to increase welfare (Grin, 2003). Our collective answer will determine our view of LIEP, which in turn will determine our response through LIEP to language education in Barbados.

Gaps

Another challenge facing the LIEP process is the gap between policy and practice, and policy and reality. In reporting on the language policy situation in present day South African schools, Probyn (2005: 160) asserts that through research it has been found that "the majority of schools have not drawn up formal school language policies in line with the required processes and policy recommendations of the Language-in-Education Policy". Such action simply demonstrates what is already known; policy is at times enacted but not implemented. This could be for any number of reasons, but it is suggested by Probyn that timing, capacity, language attitudes and contexts play a role. Whatever the reason, however, it appears to be a colossal waste of time, money and resources to have gone through the process if policy is not going to take effect so as to at least establish its affect. This raises a concern about human support and dissemination of comprehensible information for the success of the process. I say comprehensible because sometimes in our formal capacities we tend to forget about the people we really intend to help, and so we write our reports as though they are not part of our the target audience. Our language use can be staid, sterile, technical, and pitched at a level that some educated people cannot even understand. On a project as important as LIEP, policymakers need mass support; they need the 'many' to understand what is happening even if they do not participate. They are therefore tasked with speaking people's "language", as they do when campaigning. People from all walks of life can enrich the LIEP process with their ideas. 


\section{Macrothink}

Journal of Sociological Research

ISSN 1948-5468

2013, Vol. 4, No.2

The intentional disregard of policy in practice will be another kind of challenge which results in a gap. The South African case addressed earlier by Probyn (2005) appears to be a situation where "educational practice...may be lagging behind educational policy" (Corson 1997: 156), sometimes a natural consequence of the quality and quantity of input, but other times people deliberately set out to sabotage the process. Probyn (2005), once again commenting on the South African situation, reveals that where the recommendation of the LIEP has been to use the students' home language as a medium of instruction, the recommendation has largely been ignored. This should not be surprising, even if disappointing, as Spolsky (2004: 8) acknowledges that even where "there is a formal written language policy, its effect on language practices is neither guaranteed nor consistent". He further adds: "nor does implementation guarantee success" (p. 11). This raises a very important point as to why policies are not being implemented. Teachers are essential at this juncture, which leaves me to wonder if they are involved in the process from the start. Some might argue that this is simply passive resistance on the part of teachers who already feel burdened by other policies which resolve nothing. So what if it is, the question still comes back to why this attitude? Do teachers feel that this is just another top-down measure to flex political muscle, or might it be that because language teachers were uninvolved in the initial process they genuinely do not understand how to implement the policy and do not know what is required of them to do so? Probably, they do not have the knowledge or skills to implement the policy in their present state, or more profoundly; perhaps, based on their teaching expertise and experience, they recognize it to be bad policy and feel it to be their duty not to implement it. The fact is that to avoid such challenges in the first place, teachers must be part of the process from beginning to end, and policymakers should take their professional advice to heart in designing LIEP. This continuous open dialogue with implementers of LIEP will lessen the chances of sabotage or inactivity at the stage of implementation.

Another reason for this gap between policy and practice is that policies sometimes contradict research findings about language and language learning Shohamy (2006). Essentially, policymakers ignore sociolinguistic realities or are unaware of them because they do not do their research on the research. Baldauf and Kaplan (2004: 9) really encapsulate my conclusion on this issue, though speaking specifically to policy in African states. They say that in several instances, "the "official" policy/plan is diametrically opposed to reality". Unfortunately, the linguistic reality by which many policymakers live is based on several myths founded and grounded educational systems which researchers like me are now asking them to reform, but which has shaped their success. I call it the double-edged sword. The myths all branch out of the ideology that vernacular languages are bad and standard languages are good because the former is linked to poverty and under-privilege status. If one does not wish to be associated with that group s/he will learn the standard for purposes of social and economic mobilization. This thinking might in fact not be incorrect on all levels, but it does perpetuate the myth that the only way to learn a language is to make it the medium of instruction (John, 1969), and that if the goal is proficiency in a language, the more time spent educating the learner in that language the better (Baldauf \& Kaplan 2004: 6). Unfortunately, as educators in Barbados, we only have to look at national and regional exam 
results in English and other areas to know that these contentions are indeed very flawed.

At times the challenge presents as a conflict between policy and cultural heritage. This statement, in relation to Barbados, raises some very interesting and complex issues. For example, does acquiring the new language mean that the learners have to completely assimilate into that culture? What about students' own cultural identities, how will they be affected? These were all issues officials faced in Korea when planning their English language policies. They chose to get around them by marketing English as an international language, and taking the position that early foreign language learning promotes appreciation for their own culture and others. While there were obvious successes, affective and academic, teachers still felt that the New Elementary English programme, a direct output from the new policy, accelerated the dominance of English in Korean education and undermined commitment to Korean language and cultural practices (Jung \& Norton, 2000). This draws attention to the need for finding a delicate balance between preservation of cultural identity and assimilation of second language culture. Nevertheless, I suspect that this is a balance which lies more with the students' choices, than with language policy, or teaching methodology.

\section{Conclusions and Recommendations}

\section{Research question 4: What can we learn?}

Language experts have past the stage of debating which language should be the medium of instruction. Ferguson (2010: 151) for example notes about the post-colonial African situation that there is "widespread academic agreement that the mother tongue...is, in principle, the most suitable medium for education in the initial years of education". He then goes on to justify the claims made:

Instruction in a language familiar to pupils improves immeasurably the quality of interaction between teacher and pupil. It also narrows the psychological gulf between home and school, integrates the school better into the local community and gives recognition to the language and culture the child brings to school with positive effects on the self-esteem of individuals and local communities...moreover...consolidation of the child's L1 facilitates subsequent acquisition of a second language (ibid: 151-152).

As part of the LIEP process, policymakers should investigate ways in which BD can be incorporated in a systematic way into the classroom, recognising that SE must not be relegated nor by any means replaced. The idea is to research the kinds of additive programmes which will best suit the sociolinguistic setting. In this way we instruct children in the language they know so that they can learn the language they need to know and educate themselves about all the things they do not know.

Teacher training will be a dominant factor to the success of LIEP. ELTs should be required to receive training in research techniques so that they can use these skills to good use in conducting action research in their schools. This is at least one factor which is within the school's ambit of control (Corson 1997: 160). In Singapore for example, Berry (2013) lauds the educational system which allows teachers about 15 hours a week to be involved in, 
among other things, action research. The result, according to him, is that these conditions "allow teachers to teach effectively" (p. 190); thus, he recommends, as do I, that policymakers use evidence from research to assess conditions that allow teachers to teach effectively and build into policy, measures that will create these conditions for teachers. LIEP can encourage teachers to get involved in action research through competitions or other measures, but this kind of vision must be exploited because ELTs are "on the ground" and they have special insights into education that outside researchers do not. The result can only be an even more sensitized, insightful work-force with the skills to address many of their own educational challenges in a meaningful way through research.

Teachers will also have to be trained in other areas and will require further support. The problem is that teachers have too many pieces of knowledge about language and education, training needs to help them to put the pieces together to form a cohesive pattern for practice. The key here is quality training and all ELTs need to have opportunity and access to quality programmes. This training should be designed to help teachers identify and articulate the language problems which students face, and that they themselves face in carrying out their duties. This would require training in formal Linguistics to help them get a good grasp of the structure of the language, both BD and SE. Most importantly, these training programmes should emphasise the use of language in social contexts, while also training teachers in techniques and strategies geared towards teaching English as a second dialect. In any event, this training alone should not determine teaching competency, teacher trainers should be skilled enough to "determine when teachers are ready to teach independently, in what schools and under what conditions (Berry, 2013: 188), so trainers must play a critical role in this process. This really demonstrates a need for all persons in the LIEP process to be adequately trained in their own fields, as well as to work with policymakers (Berry, 2013). ELTs need also to be trained in critiquing policy and advocating good policy. In short, ELTs need to be some of the best trained professionals because the stakes are so high. I have also extrapolated from Berry's point about trainers, a need for support within the classroom. After their training, teachers still need guidance in the actual classroom, and this can be had through mentorship programmes, supervised by more knowledgeable, more experienced, perhaps even notable retired ELTs. There will be implications in terms of remuneration and time-off to facilitate such programmes. Nevertheless, the trade-off is that new and inexperienced teachers begin to feel more confident and supported in their teaching and are perhaps more willing to volunteer, in time, when others require the same assistance. The point is that new language teachers should not be thrown into the teaching arena, expecting to cope with classroom management, methodologies, content knowledge, and their own insecurities. Perhaps, the LIEP process could require that training colleges become simulation classrooms. Undoubtedly then, teachers have a large part to play in the LIEP process from beginning to end. As the implementers they need to know what to implement, when to implement it, why it should be implemented and how. This is made easier through continual involvement in the process, so that they have an intimate knowledge of the affairs of the policy.

Policymakers have a serious responsibility in and to this process. In addition to teachers, they 
also need to employ other kinds of language experts, linguists, at every phase of planning. In Jamaica a draft policy was put forward after extensive collaboration with the Jamaican Language Unit at The University of the West Indies, Mona campus, in Jamaica. The throughput of the collaboration was the Bilingual Education Project which was designed to meet the needs of large numbers of students who came to school speaking Jamaican Creole. As a result of this project, there were gains in SE, as well as other academic successes. It also yielded the draft language education policy which set out five specific options for bilingual education in that country (The Jamaican Language Unit website). Each option included the use of the vernacular language. Such an approach demonstrates the need to see LIEP as a collaborative effort rather than just a political one. These collaborations with teachers and linguists present an opportunity, as in the case of Malaysia, for bringing together a top-down approach by "focusing on policy and planning decisions" and a bottom-up approach of "what is actually happening at the classroom level" (Martin, 2005: 74). This allows for an exploration of how practice engages or disengages with policy and the tensions that may pertain" (ibid).

Policymakers have more of a responsibility than finding expert help. They need too to get involved in constant evaluation of the process, questioning it and monitoring it to ensure that it squares with public policy and language rights. Shohamy (2006: 165) proposes that the mechanisms which drive language policy "should be regularly monitored and evaluated in order to ensure that personal rights are protected". She strongly contends that individuals at all levels should be able to question language policy and find ways to renegotiate it. On the basis of this evaluation, I recommend that LIEP be made accessible to the public for critique. People at every level must have the right and be informed of this right publicly, perhaps through public announcements, to critique these policies, but they should do so with informed insight. Policymakers too are responsible for ensuring that the policy makes allowance for the creation of links between home and school, and most importantly, they are charged with the hefty responsibility of never underestimating this process by oversimplifying the complexity of the issues involved, but neither should they complicate the process by making simple issues more complex.

Policy needs to present a revised and more in-touch view of language, language learning and language education. The case of Korea typifies this suggestion. The Korean situation demonstrated the need for a change in teaching methodologies based on a change in views about the purpose of language education. When Korean policymakers entered into a campaign of globalisation, they began to recognise the need for a change in the way English was taught. English was taught for academic purposes and so the focus was on grammar and reading for higher education. However, with a shift in political focus there needed to be a shift in the view of the purpose of language, language education and ultimately, teaching methodology. With a new emphasis on oral and communicative proficiency in English, the New Elementary English Program was born. The programme reaped many successes including increased motivation among students to learn the language, better trained and more competent teachers and more academic success in the language for the students. Korea 
ensured that the resources for success were put in place. The government also ensured that every elementary teacher was trained over a two year period. There were initiatives put in place for teachers to receive more training and to test teachers' oral proficiency. Teachers needed to be competent to get the job and/or retain it, for as Kaplan (1997: xx) asserts, "the issue of standards - not the issue of standardization - must be addressed; there must be minimum standards for entry into the field generally". Wren's (1997: 26) perspective on this issue is in line with the action taken by the Korean government to ensure teacher competence. She advises that teachers first ensure their linguistic mastery and quality of teaching in the language before they can be responsible for others'. I urge one caution: that only after training in the language, should ELTs be tested as to their level of linguistic proficiency.

The case of Korea has many other positive points on which the Barbadian situation can draw. For example, there was seemingly adequate and proper preparation prior to embarking on this huge undertaking and the implementers were given the necessary tools and skills. The recommendation here is to first determine the goal of language education for the Barbadian citizenry and weigh it against the goals of other policies, national and foreign. Do not be afraid to realign views if they seem out of sync with certain policy goals. Determine how the practical aspects of this LIEP will be financed, what resources will be needed, and how they will be funded so that there is no start-stop mentality. I will therefore present my expectations for LIEP as a series of recommendations, rather than as a step-by-step procedure, for I recognise the process to be a potentially messy one.

- Rec 1: Diagnose the language problem(s)

- $\operatorname{Rec} 2$ : Examine the social context, focusing on social and linguistic reality

- Rec 3: Do not oversimplify/underestimate/complicate the process

- Rec 4: Make research the basis on which policy is founded

- Rec 5: Use a combination of top-down, bottom up approaches

- Rec 6: Design and monitor policy with input from experts and non-experts

- $\operatorname{Rec} 7$ : Critique the policy in line with public interests

- Rec 8: Modify, maintain/ reject policy or aspects of it

- Rec 9: OWN the policy, market and sell the policy

- Rec 10 Ensure a solid link between the community and the school

\section{Summative Conclusion}

I have come to the following conclusions in line with the research questions. A language policy in the Barbadian context is really a language-in-education policy, that is, how language can and should be used within the educational system for the purposes of educating the entire child so that s/he can use this language(s) within socially appropriate settings; rather, than just for academic success. I believe, as does Kaplan (1997) that the role of the language teacher and language education is so important that without them no other disciplines could function. It is the language teacher that lays the foundation for all other academic study and what a student learns beyond formal schooling. In light of Kaplan's views, which I wholeheartedly endorse, language education needs to be taken much more seriously in Barbados. This can be done by examining the implicit policies and ideologies that shape language education and 
reshape them to formulate an explicit cohesive policy to guide and assist language education and educators in the country. Such a policy, where properly informed by socio-cultural, socio-historical and sociolinguistic factors and where society is always at its core, has the potential to help the educational system overcome real challenges to social equity for the disadvantaged. This in turn has the potential of improving the quality of life throughout the nation and hence, the economics of that nation, for an educated nation will be a strong nation even if just in terms of human capital. I also believe that LIEP for Barbados must thoroughly address language teacher knowledge, skills and training in order to restructure the system for success. Such a policy must invariably address the purpose of language education for the well-being of all other kinds of education.

A better understanding of the social context will give the LIEP movement a real thrust. A thorough examination will assist in better understanding the ideologies which underpin language practices. In fact, Ricento (2000) confidently stands by the research in the field that "demonstrates that language policies can never be properly understood or analyzed as free-standing documents or practices; to ignore the role of ideology...is to engage in ideological subterfuge of the worst sort" (p. 6). We can only shape a responsive LIEP when we understand the needs for which we shape them. Those needs belong to someone, to some face, in many cases to some voiceless voice. When we think of LIEP in Barbados, I want policymakers to see people, real faces, their daughters, sons, cousins, grand-children, their constituents, faces of people who benefit, who query, who apply, modify and reject for the sake of best practices. I need them to see real people, with real faces so that they begin to feel the pain of policy impact when it is inappropriate and the joys when it is appropriate. When we begin to see faces in policy and give voices to the voiceless through policy, we begin to approach its design with a sense of awe and perhaps even a little trepidation, for after all, real people are counting on a LIEP policy that addresses their real needs and impacts their very real hopes of a future. An LIEP process in the Barbadian context must give face and voice to policy if it will reap real success.

\section{References}

Aberg, A., \& Waller, J. (2012). English language teachers' perception of their role and responsibility in three secondary schools in Jamaica. Retrieved from dspace.mah.se/handle/2043/13434

Baldauf, R., \& Kaplan, R. (2004). Language planning and policy in Botswana, Malawi, Mozambique and South Africa: Some common issues. In R. Baldauf \& R. Kaplan (Eds.), Language planning and policy in Africa Vol.1: Botswana, Malawi, Mozambique and South Africa (pp.5-20). Clevedon, UK: Multilingual Matters.

Ball, S. (1994). Education Reform: A critical and post-structural approach. Buckingham: Open University Press.

Barkhuizen, G. P., \& Gough, D. (1996). Language curriculum development in South Africa. TESOL Quarterly, 30(3), 453-472. 


\section{Macrothink}

Berry, B. (2013). Good schools and teachers for all students: Dispelling myths, facing evidence and pursuing the right strategies. In P. Carter, P. \& K. Welner (Eds.), Closing the opportunity gap: What America must do to give every child an even chance (pp. 181-192). Oxford: OUP.

Bourne, J. (1997). The grown-ups know best: Language-policy making in Britain in the 1990s. In W. Eggington \& H. Wren (Eds.), Language Policy: Dominant English, Pluralist Challenges (pp. 49-65). Philadelphia, PA: John Benjamins.

Caribbean Examinations Council. (2013). CSEC Results: English A. Retrieved from www.cxc.org/examinations/exam-results-reports

Carr, W., \& Kemmis, S. (1986). Becoming critical: Education, knowledge and action research. London: Falmer.

Carrington, L. (1976). Determining language education policy in Caribbean sociolinguistic complexes. Linguistics: An International Review, 175, 27-43.

Christie, P. (1991). The right to learn: The struggle for education in South Africa. Ravan Press: Johannesburg: South Africa.

Corson, D. (1997). Social Justice in the work of ESL teachers. In W. Eggington \& H. Wren (Eds.), Language Policy: Dominant English, Pluralist Challenges (pp. 149-163). Philadelphia, PA: John Benjamins.

Craith, M. N. (2006). Europe and the politics of language: Citizens migrants and outsiders. New York, NY: Palgrave Macmillan.

Cumming, A. (1997). English language-in-education policies in Canada. In W. Eggington \& H. Wren (Eds.), Language Policy: Dominant English, Pluralist Challenges (pp. 91-105). Philadelphia, PA: John Benjamins.

Denny, S. (2002). We survived the inhumanity, but do we still wear the shackles?: An investigation into teachers' attitudes to the use of Barbadian dialect as an instructional tool in primary schools. Unpublished doctoral thesis, University of Exeter, Exeter, UK.

Denny, S. (2007). Fully facing facts: Teach the teachers then talk yuh talk. La Torre, 46, 519-544.

Denny, S. (2010). The ABCs of teacher language proficiency. In N. Faraclas, R. Severing, C. Weijer, E. Echteld, M. Hinds-Layne \& E. Lawton de Torruella (Eds), In a sea of heteroglossia: Pluri-lingualism, pluri-culturalism, and pluri-identification in the Caribbean (pp. 135-152). Williamstead: Fundashon pa Planifikashon di Idioma.

Eggington, W. (1997a). The English language metaphors we plan by. In W. Eggington \& H. Wren (Eds.), Language Policy: Dominant English, Pluralist Challenges (pp. 29-46). Philadelphia, PA: John Benjamins.

Egginton, W. (1997b). The roles and responsibilities of ESL teachers within national policies. In W. Eggington \& H. Wren (Eds.), Language Policy: Dominant English, Pluralist Challenges (pp. 165-168). Philadelphia, PA: John Benjamins.

Fatihi, A. R. (2001). Politics of language and language identity- A case of Urdu. In O. Koul \& P. Umarani (Eds.), Sociolinguistics and language education (A Festschrift for Dr. D. P. Pattanayak) (pp. 87-95). New Delhi: Creative Books.

Ferguson, G. (2010). Language education policy and the medium of instruction issue in post-colonial Africa. In M. Meyerhoff \& E. Schleef (Eds), The Routledge Sociolinguistics 
Reader (pp. 150-167): New York, NY: Routledge.

Grin, F. (2003). Language policy evaluation and the European charter for regional or minority languages. New York, NY: Palgrave Macmillan.

Haugen, E. (1966). Linguistics and language planning. In W. Bright (Ed.), Sociolinguistics (pp. 50-71). The Hague: Mouton.

Hebblethwaite, B.(2012). Educational language policy problems and solutions in Haiti. Journal of Pidgin and Creole Languages, 27(2), 255-302.

John, V. V. (1969). Education and language policy. Bombay: Nachiketa Publications.

Jung, S. K., \& Norton, B. (2002). Language planning in Korea: The New Elementary English Program. In J. Tollefson (Ed.), Language policies in education: Critical Issues (pp. 245-265). Mahwah, NJ: Lawrence Erlbaum.

Kaplan, R. (1997). Foreword. In W. Eggington, H. Wren (Eds.), Language Policy: Dominant English, Pluralist Challenges. Philadelphia, PA: John Benjamins.

Kayambazinthu, E. (2004). The language planning situation in Malawi. In R. Baldauf \& R. Kaplan (Eds.), Language planning and policy in Africa Vol.1: Botswana, Malawi, Mozambique and South Africa (pp. 79-149). Clevedon, UK: Multilingual Matters.

Kennedy, M. (1991). Some surprising findings on how teachers learn to teach. Educational Leadership, 49(3), 14-17.

Martin, P. (2005). Language practices in two rural schools in Malaysia: Tensions between policy and practice. In A. Lin \& P. Martin (Eds.), Decolonisation, globalisation: Language-in-education policy and practice (pp. 74-97). Tonawanda, NY: Multilingual Matters.

McCourtie, L. (1998). The politics of creole language education in Jamaica: 1891-1921 and the 1990s. Journal of Multilingual and Multicultural Development, 19(2), 108-127.

McGroarty, M. (1997). Language policy in the USA: National values, local loyalties, pragmatic pressures. In W. Eggington \& H. Wren (Eds.), Language Policy: Dominant English, Pluralist Challenges (pp. 67-90). Philadelphia, PA: John Benjamins.

McGroarty, M. (2002). Evolving influences on educational language policies. In J. Tollefson (Ed.), Language policies in education: Critical issues (pp. 17-36). Mahwah, NJ: Lawrence Erlbaum.

Ministry of Education Youth Affairs and Culture. (2000). Education in Barbados Information Handbook. Bridgetown: Barbados: The Planning and Research Section.

Ministry of Education and Human Resource Development. Primary Language Arts Syllabus. Bridgetown: Barbados.

Mungabhai, F., \& Mugler, F. (2006). The language situation in Fiji. In R. Baldauf \& R. Kaplan (Eds.), Language planning and policy in Africa Vol.1: Botswana, Malawi, Mozambique and South Africa (pp. 22-113). Clevedon, UK: Multilingual Matters.

Nyati-Ramahobo, L. (2004). The language situation in Botswana. In R. Baldauf \& R. Kaplan (Eds.), Language planning and policy in Africa. Vol.1: Botswana, Malawi, Mozambique and South Africa (pp. 21-78). Clevedon, UK: Multilingual Matters.

Obidah, Jennifer (Feb. 25, 2011). Teacher Development in the Region: Knowing what was, what is, what should be? Panel discussion held at The University of the West Indies, Cave Hill Campus, Bridgetown, Barbados. Retrieved from 
Www.nationnnews.com/articles/too-many-untrained-teachers

Pennycook, A. (1994). The cultural politics of English as an international language. London: Longman.

Pennycook, A. (2000). Language ideology and hindsight: Lessons from colonial language policies. In T. Ricento (Ed.), Ideology, Politics and language policies: Focus on English (pp. 49-65). Philadelphia, PA: John Benjamins.

Phillipson, R. (2003). English-only Europe? Challenging language policy. London: Routledge.

Probyn, M. (2005). Language and the struggle to learn: The intersection of classroom realities, language policy, and neo-colonial and globalisation discourses in South African schools. In A.

Lin \& P. Martin (Eds.), Decolonisation, globalisation: Language-in-education policy and practice (pp. 153-172). Tonawanda, NY: Multilingual Matters.

Reagan, T. (2010). Language policy and planning for sign languages. Washington, DC: Gallaudet University Press.

Ricento, T. (2000). Ideology, Politics and language policies. In T. Ricento (Ed.), Ideology, Politics and language policies: Focus on English (pp. 1-8). Philadelphia, PA: John Benjamins.

Robertson, I. (1996). Language education policy 1: Towards a rational approach for Caribbean states. In P. Christie (Ed.), Caribbean language issues: Old and new (pp. 112-119). Mona: UWI Press.

Shohamy, E. (2006). Language policy: Hidden agenda and new approaches. New York, NY: Routledge.

Siegel, J. (1997). Using a pidgin language in formal education: Help or hindrance? Applied Linguistics, 18(1), 86-100.

Spolsky, B. (2004). Language Policy. Cambridge: CUP.

Spolsky, B. (2009). Language management. Cambridge: CUP.

The Jamaican Language Unit. Bilingual Education Project. Retrieved from www.mona.uwi.edu/dllp/jlu/projects

Tollefson, J. (1991). Planning language, planning inequality. London: Longman.

Tollefson, J. (2002). Critical issues in educational language policy. In J. Tollefson (Ed.), Language policies in education: Critical Issues (pp. 3-15). Mahwah, NJ: Lawrence Erlbaum.

Welner, K., \& Carter, P. (2013). Achievement gaps arise from opportunity gaps. In P. Carter \& K. Welner (Eds.), Closing the opportunity gap: What America must do to give every child an even chance (pp. 1-10). Oxford: OUP.

Wren, H. (1997). Making a difference in language policy agendas. In W. Eggington \& H. Wren (Eds.), Language Policy: Dominant English, Pluralist Challenges (pp. 3-28). Philadelphia, PA: John Benjamins.

Wright, S. (2004). Language policy and language planning: From nationalism to globalisation. New York, NY: Palgrave Macmillan. 
Appendix 1

Barbados Secondary Schools' Entrance Examination (BSSE) English language results 2008-2012

\begin{tabular}{|c|c|c|c|c|c|c|c|c|c|c|}
\hline YEAR & \multicolumn{2}{|c|}{2008} & \multicolumn{2}{|c|}{2009} & \multicolumn{2}{|c|}{2010} & \multicolumn{2}{|c|}{2011} & \multicolumn{2}{|c|}{2012} \\
\hline $\begin{array}{l}\% \\
\text { range }\end{array}$ & $\begin{array}{l}\text { Raw } \\
\text { score/3692 }\end{array}$ & $\%$ & Raw/3583 & $\%$ & Raw/3673 & & Raw/3767 & & Raw/3970 & \\
\hline $90-99$ & 80 & .02 & 171 & .05 & 247 & .07 & 181 & .05 & 370 & .09 \\
\hline $80-89$ & 444 & & 572 & & 707 & .19 & 851 & .22 & 840 & .21 \\
\hline $70-79$ & 577 & & 614 & .17 & 694 & & 809 & & 786 & \\
\hline $60-69$ & 584 & .15 & 537 & & 515 & & 585 & & 536 & \\
\hline $50-59$ & 499 & .12 & 441 & .12 & 429 & & 413 & & 390 & \\
\hline $40-49$ & 455 & .12 & 395 & & 331 & & 319 & & 338 & \\
\hline $30-39$ & 442 & .12 & 361 & & 246 & & 221 & & 279 & \\
\hline $20-29$ & 333 & & 293 & & 237 & & 187 & & 247 & \\
\hline $10-19$ & 261 & & 181 & & 248 & & 189 & & 169 & \\
\hline $1-9$ & 16 & & 18 & & 19 & & 12 & & 11 & \\
\hline 0 & 1 & & - & & - & & - & & - & \\
\hline
\end{tabular}

Caribbean Examinations Council English A results 2008-2012

\begin{tabular}{|l|l|l|l|l|l|l|l|l|l|l|l|}
\hline YEAR & \multicolumn{2}{|c|}{ 2008 } & \multicolumn{3}{c|}{ 2009 } & \multicolumn{2}{c|}{ 2010 2011 } & \multicolumn{2}{c|}{2012} \\
\hline $\begin{array}{l}\text { Range } \\
\text { score/3692 }\end{array}$ & Raw/3583 & \% & Raw/3673 & & Raw/3767 & & Raw/3970 & \\
\hline $90-99$ & 80 & .02 & 171 & .05 & 247 & .07 & 181 & .05 & 370 & .09 \\
\hline $80-89$ & 444 & & 572 & & 707 & .19 & 851 & .22 & 840 & .21 \\
\hline $70-79$ & 577 & & 614 & .17 & 694 & & 809 & & 786 & \\
\hline $60-69$ & 584 & .15 & 537 & & 515 & & 585 & & 536 & \\
\hline $50-59$ & 499 & .12 & 441 & .12 & 429 & & 413 & & 390 & \\
\hline $40-49$ & 455 & .12 & 395 & & 331 & & 319 & & 338 & \\
\hline $30-39$ & 442 & .12 & 361 & & 246 & & 221 & & 279 & \\
\hline $20-29$ & 333 & & 293 & & 237 & & 187 & & 247 \\
\hline $10-19$ & 261 & & 181 & & 248 & & 189 & & 169 & \\
\hline $1-9$ & 16 & & 18 & & 19 & & 12 & & 11 \\
\hline 0 & 1 & & - & & - & & - & - & \\
\hline
\end{tabular}

